\title{
Preparation, Characterization and In vitro Evaluation of Poly (L-lactide) and Sodium Calcium Silicate Ceramic Composites
}

\author{
M.I. El-Gohary, Gehan M. Kamal", Sahar M. Awad", \\ Abeer M. El-Kady ** and Areg E. Omar* \\ Physics Department Faculty of Science (boys); Physics \\ Department Faculty of Science, (girls), Al-Azhar University, \\ Nasr City and ${ }^{* *}$ Biomaterials Department, National Research \\ Center, Cairo, Egypt.
}

7 HE MAIN objectives of the present study were to fabricate sodium calcium silicate ceramic/poly(L-lactide) composite membranes for bone engineering applications, by using liquid-liquid phase separation. The membranes were characterized by SEM, FT-IR, TGA and TF- XRD. Examination of the SEM microphotographs revealed that the pore diameter of the composites decreased as the ceramic content increased. For the composites containing ceramic content of $20 \mathrm{wt} \%$ (CP20) and $30 \mathrm{wt} \%$ (CP30), the maximum pore diameter was $70 \mu \mathrm{m}$ and $55 \mu \mathrm{m}$, respectively.

In vitro bioactivity evaluation showed that the composites were able to induce the formation of hydroxyapaptite layer on their surfaces, demonstrating their potential application in bone engineering.

Keywords: Poly (L-lactide), Sodium calcium silicate ceramic, Sol-gel.

Among the biodegradable polymers, poly L lactide (PLA) have been receiving a special interest as biomedical materials, PLA has widespread applications in sutures, drug delivery devices, prosthetics, scaffolds, vascular grafts, bone screws, pins, a bone reinforcement material and plates for temporary internal fixation $^{(1)}$

PLA can be considered an eco-friendly biomaterial (consume carbon dioxide in its production), it is biodegradable, recyclable, biocompatible with excellent mechanical properties. However; it has many drawbacks such as it is hydrophobic, with slower degradable rate, acidic in its degradation products, in addition to its, inability to induce a bone like apatite ${ }^{(2)}$. Therefore, bioactive material such as sodium calcium silicate ceramic $^{(3)}$ is added to the prepared composites.

\section{Material and Methods}

Materials

Tetraethyl orthosilicate (TEOS), calcium nitrate tetrahydrate, $\mathrm{Ca}\left(\mathrm{NO}_{3}\right)_{2} \cdot 4 \mathrm{H}_{2} \mathrm{O}$, were all $\geq 98 \%$ pure and purchased from Fluka (Buchs, Switzerland). Sodium nitrate 
$\left(\mathrm{NaNO}_{3}\right)$ was purchased from Sigma Aldrich. Ammonia solution, 33\%, and Nitric acid, 68\%, were obtained from Merck, USA. Poly (L-lactide) (M. Wt. 152,000) was obtained from Fluka, USA. Chloroform was obtained from Acros (Acros Organics, Belgium). Both nitric acid and ammonia solutions were diluted to $2 \mathrm{M}$ using distilled water.

Preparation of bioactive sodium calcium silicate ceramic $\left(\mathrm{Na}_{4} \mathrm{Ca}_{4} \mathrm{Si}_{6} \mathrm{O}_{18}\right)$ by solgel method

$\mathrm{Na}_{4} \mathrm{Ca}_{4} \mathrm{Si}_{6} \mathrm{O}_{18}$ was prepared using the sol-gel technique and the preparation procedure was similar to the preparation of bioactive glass $58 \mathrm{~S}^{(3)}$. The previous method was modified through a quick alkali mediated sol gel technique to obtain nano ceramic particles.

Preparation of biocomposites based on poly L-lactide and contain sodium calcium silicate ceramic particles as a filler

The composite membranes were prepared through the liquid-liquid phase separation as illustrated elsewhere ${ }^{(4,5)}$. Briefly, poly (L-lactide) was dissolved in chloroform to form a polymer solution with a concentration of $10 \%(\mathrm{w} / \mathrm{v})$. Bioactive ceramic powder was added and the mixture stirred for $3 \mathrm{hr}$ to ensure the complete dissolution of the polymer and the formation of a homogenous solution. Then the solution poured into a closed petri dish and frozen at $-20{ }^{\circ} \mathrm{C}$ for 2 days after that the dish was opened and still in freezing for 1 day to allow chloroform to evaporate. This lead to the formation of the porous composites.

The prepared composites containing 20 and 30 wt.\% of sodium calcium silicate ceramic. The composites were denoted as CP20 and CP30 respectively.

The ceramic content in each membrane was calculated according to Eq. 1.

Ceramic content (wt. \%) $=\left\{\frac{\mathbf{W}_{\mathbf{c}}}{\mathbf{W}_{\mathbf{c}}+\mathbf{W}_{\mathbf{p}}}\right\} \quad * 100$

where $\mathrm{W}_{\mathrm{c}}$ was weight of the ceramic and $\mathrm{W}_{\mathrm{p}}$ was weight of the polymer.

\section{Characterization techniques}

The morphology and the porous structure of the composite membrane, as well as their elemental composition, were analyzed with Scanning Electron Microscopy coupled with Energy-Dispersive Spectroscopy, SEM/EDXA (JEOL JXA-840A, Electron probe micro-analyzer, Japan) at $30 \mathrm{kV}$. The scaffolds were cut with a razor blade and coated with carbon. The SEM analysis was carried out for the sample with different magnifications.

Thermogravimetric analysis (TGA) of the prepared composite was obtained. Scans were performed in an air atmosphere in a temperature range $50-500^{\circ} \mathrm{C}$ for the scaffolds at a rate of $10^{\circ} \mathrm{C} / \mathrm{min}$ using aluminum oxide powder as a reference. The phase analysis of samples was examined by an X-ray diffractometer model BRUKER axs, D8ADVANCE (Germany) employing Ni-filtered $\mathrm{Cu} \mathrm{K \alpha}$ irradiation at $40 \mathrm{kV}$ and $25 \mathrm{~mA}$.

Egypt. J. Biophys. Biomed. Engng. Vol. 16 (2015) 
The Fourier-Transform Infrared spectra, (FT-IR) of the prepared glass and the scaffolds were obtained using the FT/IR-6100 type A machine (The Netherlands) in the range of $400-4000 \mathrm{~cm}^{-1}$. Disks were prepared by mixing powders of membrane with $\mathrm{KBr}$. Pure $\mathrm{KBr}$ powder was used as a background.

\section{Assessment of in vitro bioactivity}

The assessment of the in vitro bioactivity was carried out by soaking the composites in simulated body fluid (SBF) in sterilized polyethylene containers maintained at $37^{\circ} \mathrm{C}$. The SBF had an ion concentration nearly equal to that of the human blood plasma. The SBF is prepared by dissolving reagent-grade $\mathrm{NaCl}$, $\mathrm{NaHCO}_{3}, \mathrm{KCl}, \mathrm{K}_{2} \mathrm{HPO}_{4} \cdot 3 \mathrm{H}_{2} \mathrm{O}, \mathrm{MgCl}_{2} \cdot 6 \mathrm{H}_{2} \mathrm{O}, \mathrm{CaCl}_{2}$, and $\mathrm{NaSO}_{4}$ in deionized water. The solution buffered to $\mathrm{pH} 7.4$ with Tris- hydroxymethyl aminomethane $\left(\mathrm{CH}_{2} \mathrm{OH}\right)_{3} \mathrm{CNH}_{3}$ and hydrochloricacid ${ }^{(6)}$. The samples is removed from the SBF, rinsed gently with absolute ethanol and then with deionized water, and left to dry. The formation and growth of apatite layer on the ceramic and composite surfaces were verified by Scanning Electron Microscope coupled with Energy-Dispersive Spectroscopy, SEM/EDXA (JEOL JXA-840A, Electron probe micro-analyzer, Japan), Thin-Film X-ray Diffraction (TF-XRD) (Panalytical, X'Pert Pro, The Netherlands), and Fourier-Transform Infrared spectra, (FT-IR) (6100 type A machine) in the range of $400-4000 \mathrm{~cm}^{-1}$.

\section{Results and Discussion}

\section{Results of characterizations}

Thermal analysis

The thermogravimetric analysis (TGA) of the composites were indicated in Fig. 1. The TGA results of $\mathrm{CP} 20$ and $\mathrm{CP} 30$ showed that the thermal destruction of the polymer started at $100{ }^{\circ} \mathrm{C}$ and ended at $395{ }^{\circ} \mathrm{C}$ recording a total weight loss of $80.816 \%$ and $66.53 \%$, respectively due to release of organic materials.

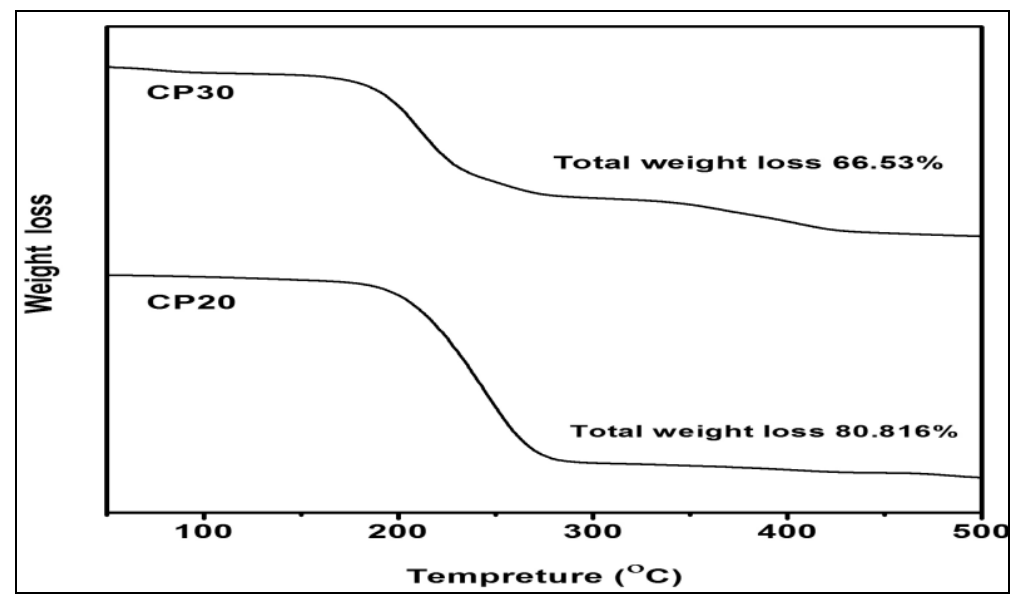

Fig. 1. Thermogravimetric analysis (TGA) of CP20 and CP30 composites.

Egypt. J. Biophys. Biomed. Engng. Vol. 16 (2015) 
The ceramic content in the fabricated composites could be calculated from the TGA data and from Equation 1 for comparison.

The ceramic content from Eq. 1 was $20 \%$ and $30 \%$ for CP20 and CP30, respectively while that from TGA was $19.184 \%$ and $33.47 \%$ for the same composites, respectively.

The comparison showed a difference between the amount of the ceramic content calculated from TGA data and those calculated by Eq. 1. Such difference might be due to some partial sedimentation of the ceramic particles during fabrication of composites ${ }^{(7)}$.

\section{SEM examination}

Figure 2 and Fig. 3 represent the SEM micrographs of a cross-section of CP20 and CP30 before immersion in SBF, respectively.
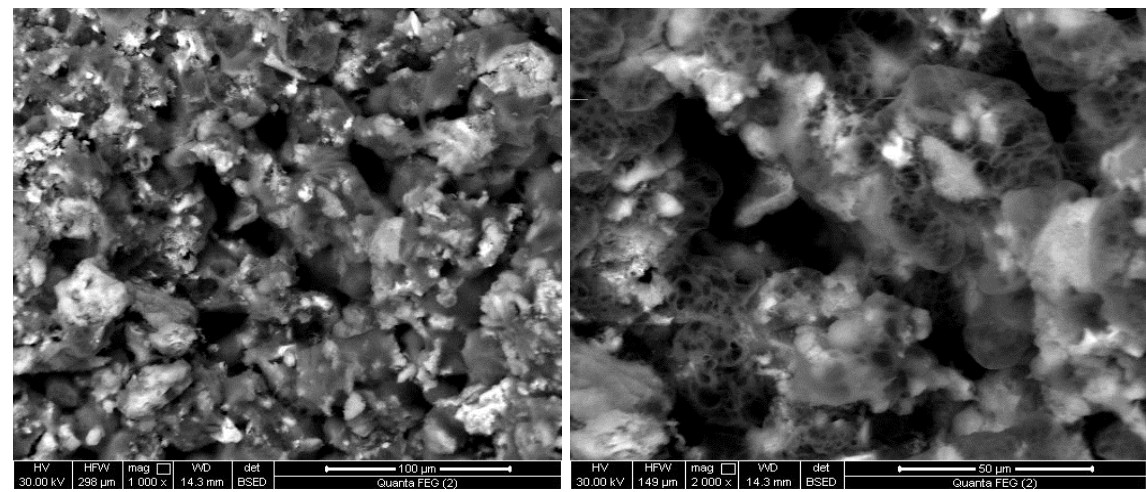

Fig. 2. SEM micrograph showing a cross-section of the composite membrane CP20. The figure shows a pore size varying from a few microns to about $70 \mu \mathrm{m}$.
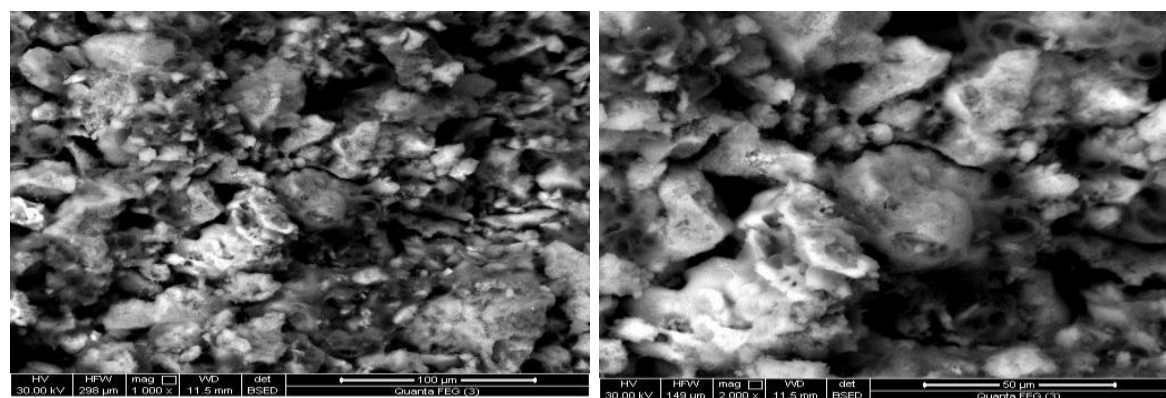

Fig. 3. SEM micrograph showing a cross-section of the composite membrane CP30. The figure shows a pore size varying from a few microns to about $55 \mu \mathrm{m}$. 
The composite membranes CP20 showed a pore size varying from a few microns to about $70 \mu \mathrm{m}$ (Fig. 2). By increasing the ceramic filler the pore size of the composites decreased, ranging from few microns to about $55 \mu \mathrm{m}$ for CP30.

In this study, the polymer solution is frozen at $-20^{\circ} \mathrm{C}$, which is higher than the freezing point of the chloroform $\left(-64^{\circ} \mathrm{C}\right)$, thus, inducing the Liquid-liquid phase separation by freezing the polymer. The SEM micrographs demonstrated that the porosity of the polymer matrix could be affected by the incorporation of bioactive ceramic. When an inorganic filler, such as ceramic added to the polymer/solvent solution, the growth of polymer crystals is impeded during the phase separation mechanism by the randomly distributed solid inorganic phase, hence the porosity of the scaffold decreases and the pores became irregular in shape (Fig. 2 and 3). Many other studies ${ }^{(8-11)}$ showed the same observations.

$X$-ray diffraction analysis

The TF-XRD patterns of the composites CP20 and CP30 before immersion in the SBF were illustrated in Fig. 4.

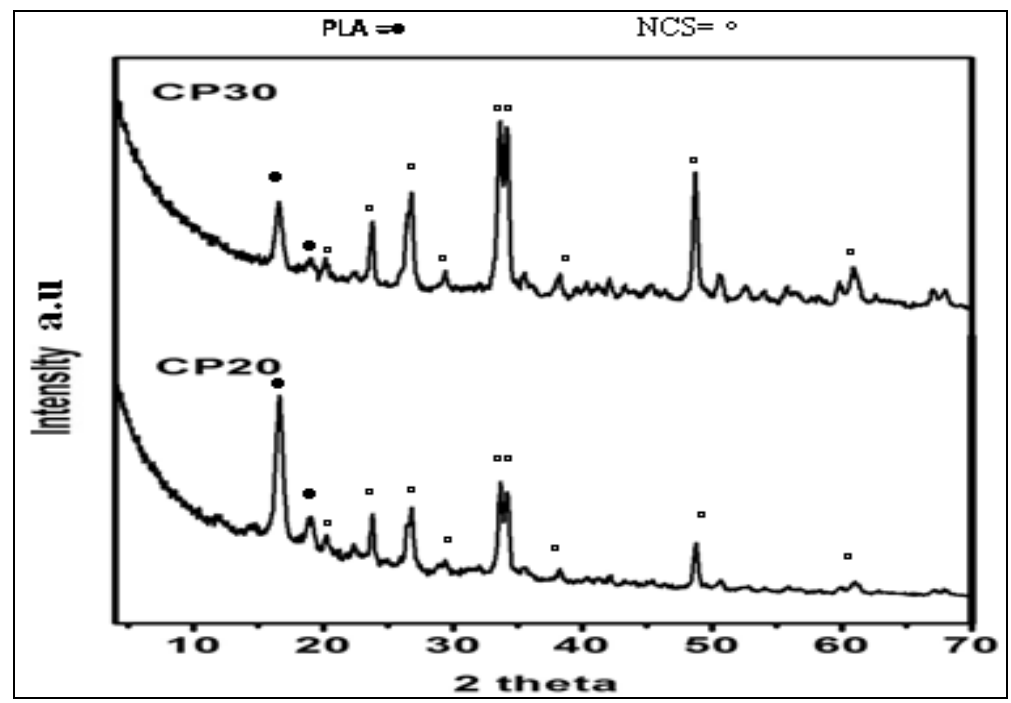

Fig. 4. Thin film X-ray of CP20, and CP30 before immersion in SBF.

For the composite membranes, two XRD peaks of the crystalline poly $(\mathrm{L}$ lactide) found at $2 \theta$ values of 16.63 and 18.86 corresponding to d-spacing of $5.34 \AA$ and $4.67 \AA$, respectively ${ }^{(12)}$. The figure also indicates that the intensity of the two peaks has gradually decreased as the ceramic filler content increased in the composite membranes. This could be attributed to the interaction between the polymer and ceramic fillers. Therefore, the two characteristic peaks of the poly(L-lactide) were masked by the ceramic fillers. 
Also all peaks of sodium calcium silicate ceramic were noticed and it was identical to peaks of the standard PDF No. 75-1687 quite well. The intensity of ceramic beaks was increased as the ceramic filler content increased.

\section{FT-IR analysis}

FTIR spectra of the composite membranes CP20 and CP30 before SBF soaking are indicated in Fig. 5.

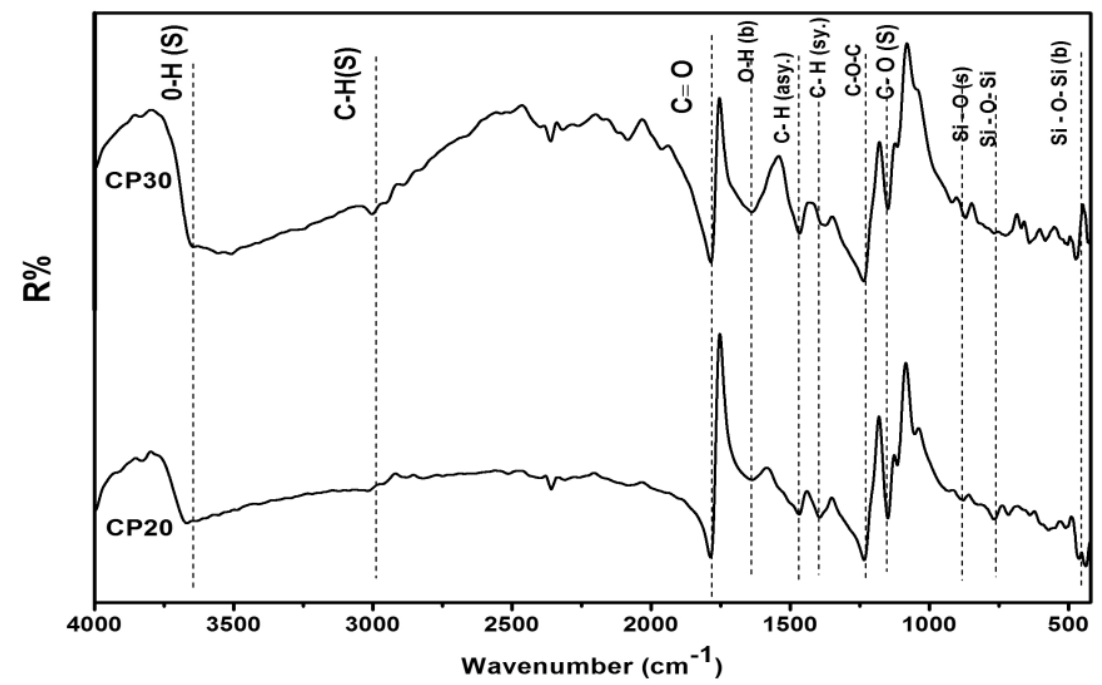

Fig. 5. FTIR spectra of the composites CP20 and CP30 before soaking in SBF. $(\mathbf{R} \%)=$ Reflectance $\%$.

FTIR spectra of the composite membranes illustrate all the characteristic absorption peaks of poly(L- lactide), and sol-gel sodium calcium silicate ceramic.

The main characteristic bands of poly(L-lactide) as reported elsewhere ${ }^{(13,14)}$, these bands are ascribed to: carbonyl modes $[\mathrm{C}=\mathrm{O}]$ at $1788 \mathrm{~cm}^{-1}$, asymmetric $\mathrm{CH}_{3}$ bending mode at $1470 \mathrm{~cm}^{-1}$, symmetric $\mathrm{CH}_{3}$ stretch at $1397 \mathrm{~cm}^{-1},[\mathrm{C}-\mathrm{O}]$ stretching mode at $1150 \mathrm{~cm}^{-1}$ and other methyl bands at $3018 \mathrm{~cm}^{-1}$.

The sol-gel sodium calcium silicate ceramic characteristic bands was reported by El Batal et al. ${ }^{(15)}$, these bands are ascribed to: $\mathrm{Si}-\mathrm{O}-\mathrm{Si}$ (b) in the range of 400$500 \mathrm{~cm}^{-1}, \mathrm{Si}-\mathrm{O}-\mathrm{Si}$ (tetrahedral) at $733 \mathrm{~cm}^{-1}, \mathrm{Si}-\mathrm{O}$ (stretch) at $922 \mathrm{~cm}^{-1}, \mathrm{Si}-\mathrm{O}-\mathrm{Si}$ (stretch) at $1042 \mathrm{~cm}^{-1}$ and additional band at wavenumbers $627 \mathrm{~cm}^{-1}$ which is due to presence of sodium calcium silicate crystalline phase ${ }^{(16)}$.

A slight shift was noticed for the main peaks of poly (L-lactide) to lower frequency which may be attributed to the interaction between the components of composites.

Egypt . J. Biophys. Biomed. Engng. Vol. 16 (2015) 
In vitro bioactivity evaluation

Scanning electron microscope coupled with energy dispersive $X$-ray analysis $(S E M / E D X)$

SEM micrographs of the surface of composite membranes CP20, and CP30 after immersion in the SBF for 15 days are shown in Fig. 6 and 7. The EDX analysis of the sample surfaces is also indicated.

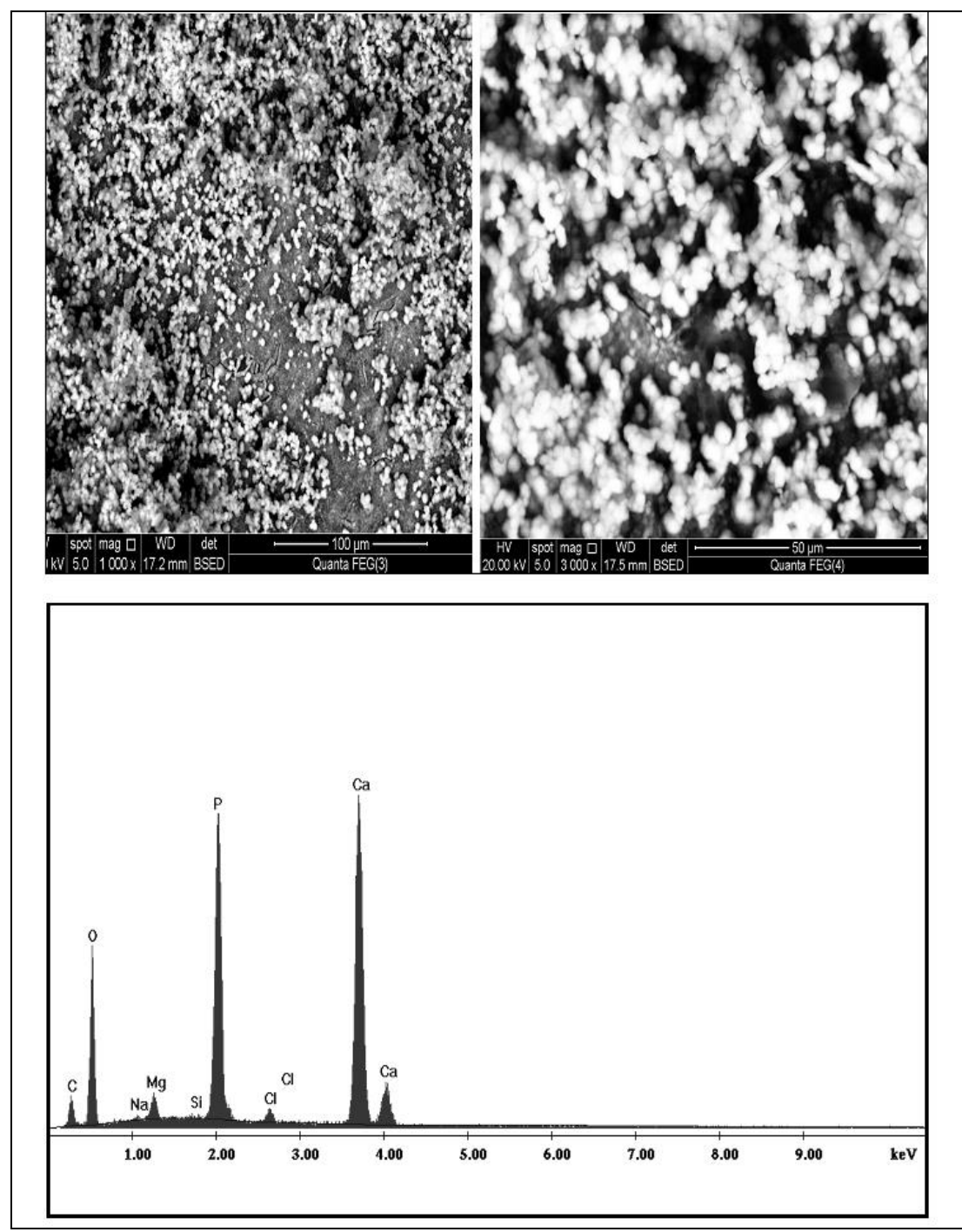

Fig. 6. SEM micrographs and EDX analysis for CP20 composite for 15 days of immersion in the SBF. 

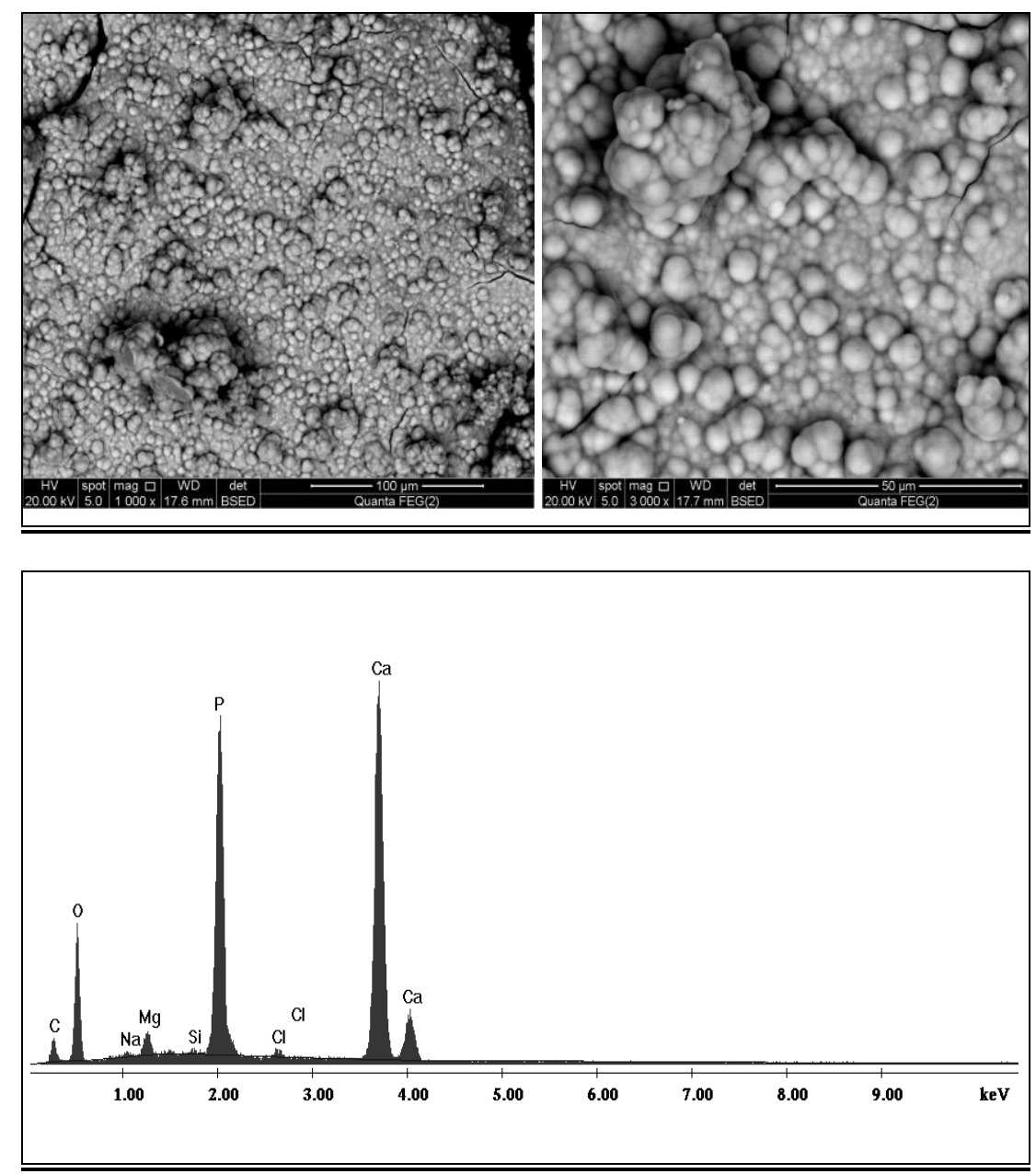

Fig. 7. SEM micrographs and EDX analysis of CP30 composites after immersion in the SBF for 15 days.

The Figures illustrate that a layer of spherical particles fully covered the surfaces of samples CP20 and CP30. The EDX analysis in these figures suggested that these spherical particles could be calcium-deficient and nonstoichiometric apatite with $\mathrm{Ca} / \mathrm{P}$ ratio of 1.37 and 1.43 for $\mathrm{CP} 20$ and $\mathrm{CP} 30$, respectively. This ratio is close to that of natural apatite in bone. Comparing the EDX analyses for both CP20 and CP30, showed that the apatite layer formed on the surface of CP30 was more mineralized than that formed on the surface of CP20. Other studies have reported that the induced apatite layer on the surfaces of different bioactive materials during their incubation in SBF was also calciumdeficient ${ }^{(12,17)}$. 
The formation of the hydroxyapatite layer on the surface of composite membranes, immersed in SBF, could be explained by the hydrolysis of ester bonds of the polymer and the formation of carboxylate groups $(\mathrm{COOH})$. These reactive groups have the ability to attract silica ions released from the scaffolds due to the dissolution of the ceramic particles.

These ions could, in turn, act as nucleation sites for calcium and phosphorus ions, leading to the formation of hydroxyapatite layer on the surfaces of the composites $^{(11,12)}$.

\section{$T F-X R D$ analysis}

The TF-XRD patterns of the surface of composite membranes (CP20 and CP30) after immersion in the SBF for 15 days is illustrated in Fig.8.

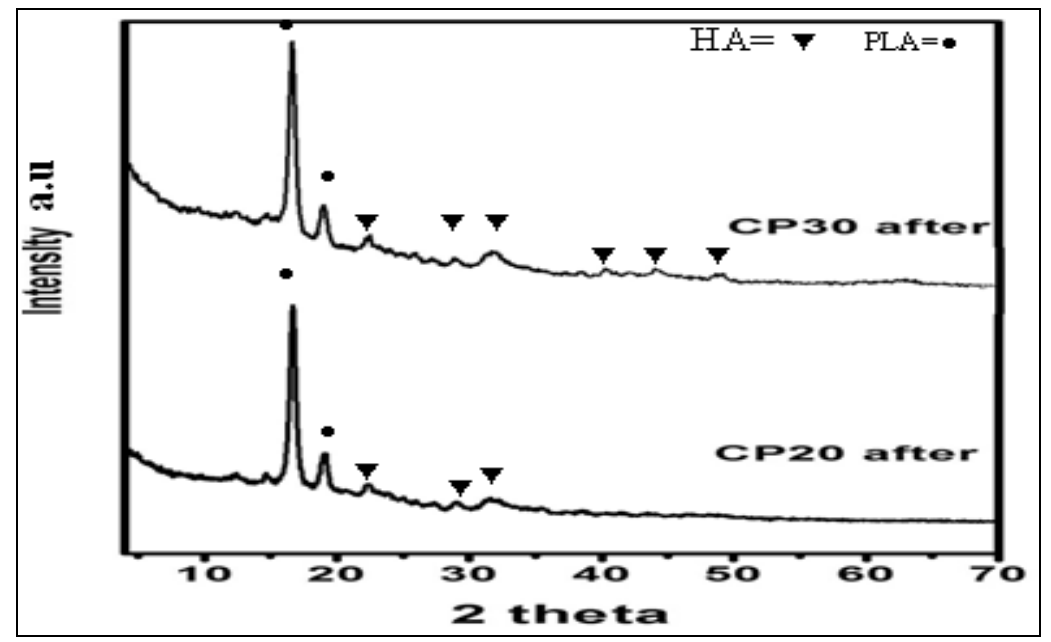

Fig. 8. Thin film X-ray analysis of $\mathrm{CP20}$ and CP30 composites after immersion in SBF for 15 days.

The Fig. shows two sharp XRD peaks of the crystalline poly(L-lactide) found at $2 \theta$ values of 16.63 and 18.86 corresponding to d-spacing of $5.34 \AA$ and $4.67 \AA$, respectively.

The figure also clearly indicate the formation of the apatite layer, on the surfaces of the samples, after 15days of immersion in the SBF.

The typical diffraction pattern of the crystalline apatite could be observed, which was associated with an evident peaks at d-spacing values of $2.81 \AA$, $2.72 \AA$ and $2.78 \AA$ [matched with the corresponding ICSD card no (82-1934)]. Those diffraction peaks became sharper and their intensity increased as the ceramic filler increase, indicating a higher apatite crystallinity. In addition, the appearance of other less intense peaks at d-spacing values of $2.44 \AA, 2.28 \AA$, 
$1.94 \AA, 1.84 \AA$ and $1.72 \AA$ [matched with the corresponding ICSD card no (821934)] is also noticed for the composite CP30. Those results further confirmed the apatite formation and crystallization for this composite.

The diffraction peak of the formed apatite at $d$-spacing value of $8.27 \AA$ was not appeared for the samples, indicating the incomplete crystallization of the apatite layer. It may be observed when immersion time in SBF increased.

FTIR analysis after soaking in SBF

Figure 9 indicates FTIR spectra of composite membranes CP20 and CP30 after 15 days of SBF immersion.

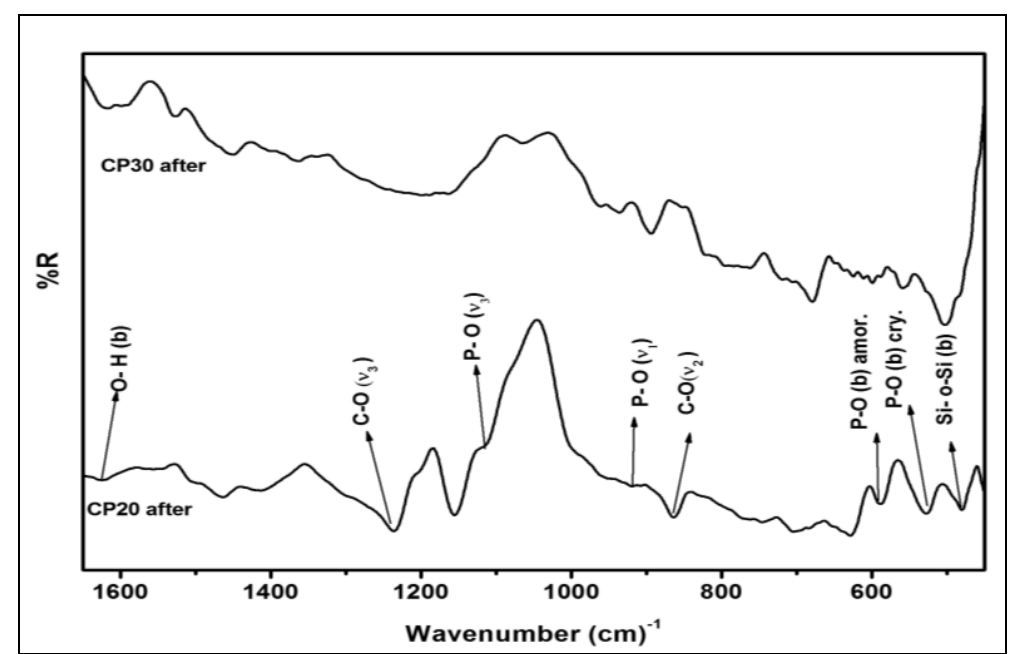

Fig. 9. FTIR spectra of CP20 and CP30 composites after soaking in SBF for 15 days. $(\mathbf{R} \%)=$ Reflectance $\%$

This Figure shows all the characteristic absorption peaks of hydroxyapetite as illustrated elsewhere ${ }^{(18-20)}$. After SBF treatment new peaks are developed for (P-O Bend- Crystalline) in the range of (500- $\left.560 \mathrm{~cm}^{-1}\right)$, (P-O Bend- Amorphous) in the range of $\left(560-600 \mathrm{~cm}^{-1}\right)$, [p-o $\left.\left(\mathrm{v}_{1}\right)\right]$ at $960 \mathrm{~cm}^{-1}$ and $\left[\mathrm{p}-\mathrm{o}\left(\mathrm{v}_{3}\right)\right]$ in the range of $(1020-$ $\left.1120 \mathrm{~cm}^{-1}\right)$, also carbonate modes are appeared as $\left[\mathrm{C}-\mathrm{O}\left(\mathrm{v}_{3}\right)\right]$ in the range of $(1350-$ $\left.1550 \mathrm{~cm}^{-1}\right),\left[\mathrm{C}-\mathrm{O}\left(\mathrm{v}_{2}\right)\right]$ stretching in the range of $\left(890-800 \mathrm{~cm}^{-1}\right)$ in addition to O$\mathrm{H}$ (b) in the range of $\left(1630-1650 \mathrm{~cm}^{-1}\right)$.

\section{Conclusion}

> The liquid-liquid phase separation used successfully in the fabrication of sodium calcium silicate ceramic/poly(L-lactide) composites. The composites show porous structure.

$>$ Increasing the ceramic concentration from $20 \mathrm{wt} . \%$ to $30 \mathrm{wt} \%$, resulted in a decrease in pore diameter from $70 \mu \mathrm{m}$ for $\mathrm{CP} 20$ to $55 \mu \mathrm{m}$ for CP30.

Egypt. J. Biophys. Biomed. Engng. Vol. 16 (2015) 
The addition of sodium calcium silicate ceramic to polymer is beneficial in the formation of hydroxyapatite layer. Therefore, it may improve polymer bone bonding ability in vivo.

\section{References}

1. Rohan, A. Hule and Darrin, J. Pochan, Polymer nanocomposites for biomedical applications. Mrs Bulletin, 32, 354-358 (2007) .

2. Puppi, D., Chiellini, F., Piras, A.M., Chiellini, E., Polymeric materials for bone and cartilage repair, Progress in Polymer Science, 35, 403-440(2010).

3. Ruilin du and Jiang chang, Preparation and characterization of bioactive sol-gelderived $\mathrm{Na}_{2} \mathrm{Ca}_{2} \mathrm{Si}_{3} \mathrm{O}_{9}$. Journal of Materials Science: Materials In Medicine, 15, 1285- 1289 (2004).

4. Peter, X. Ma Scaffold for tissue fabrication, Materials Today, 6 , 30-40 (2004).

5. Budyanto, L., Goh, Y.Q. and Ooi, C.P. Fabrication of porous poly(L-lactide) (PLLA) scaffolds for tissue engineering using liquid-liquid phase separation and freeze extraction. Journal of Materials Science: Materials in Medicine, 20,105- 111 (2009).

6. Kokubo, T. and Takadama, H. How useful is SBF in predicting in vivo bone bioactivity. Biomaterials, 27, 2907-2915 (2006).

7. Blaker, J.J., Maquet, V., Je'rôme, R., Boccaccini, A.R. and Nazhat, S.N. Mechanical properties of highly porous PDLLA/ Bioglass-composite foams as scaffolds for bone tissue engineering. Acta Biomater, 1643-652 (2005).

8. Maquet, V., Boccaccini, A.R., Pravata, L., Notingher, I. and Jerome, R. Porous poly([alpha]- hydroxyacid)/Bioglass(R) composite scaffolds for bone tissue engineering. I. Preparation and in vitro characterization. Biomaterials, 25, 4185-4194 (2004) .

9. Zhang, Kai, Wang, Yunbing, Hillmyer, A. Marc and Francis F. Lorraine Processing and properties of porous poly(L-lactide)/bioactive glass composites. Biomaterials, 25 , 2489-2500 (2004).

10. El-Kady, M.A., Ali, A.F. and Farag, M.M. Development, characterization and in vitro bioactivity studies of sol-gel bioactive glass/poly(L-lactide) nanocomposite scaffolds. Materials Science and Engineering, C 30, 120-131(2010)

11. Li, X., Shi, J., Dong, X., Zhang, L. and Zeng, H. A mesopours bioactive glass/polycaprolactone composite scaffold and its bioactivity behavior. J. Biomed. Mater. Res. 84A , 84 (2008).

12. Zhou Z., Ruan, J. and Zou, J. Bioactivity of bioresorbable composite based on bioactive glass and poly-L-lactide, Trans. Nonferrous Met. Soc. China, 17, 399-494 (2007). 
13. Anurag Pandey, Girish, C. Pandey and Pranesh, B. Aswath, Synthesis of polylactic acid-polyglycolic acid blends using microwave radiation. Journal of the Mechanical Behavior of Biomedical Materials, 1, 227 - 233 (2008).

14. Ndazi1, B.S. and Karlsson, S. Characterization of hydrolytic degradation of polylactic acid/rice hulls composites in water at different temperatures characterization of hydrolytic degradation of polylactic acid/rice hulls composites in water at different temperatures, Express Polymer Letters , 5(2),119-131 (2011).

15. El Batal, H.A., Azooz, M.A., Khalil., E.M.A, Soltan, A. and Hamdy, Y.M., Characterization of some bioglass-ceramics. Materials Chemistry and Physics, 80, 599-609 (2003).

16. Ankesh, K.S. and Ram, P. Characterization of $\mathrm{CuO}$ substituted $45 \mathrm{~S} 5$ bioactive glasses and glass - ceramics. International Journal of Scientific \& Technology Research, 1(2), 2277-8616 (2012).

17. Deng, C., Weng, J. , Lu, X., Zhou, S.B., Wan, J.X., Qu, S.X., Feng, B. and Li, X.H. Preparation and in vitro bioactivity of poly(D,L-lactide) composite containing hydroxyapatite nanocrystals. Materials Science and Engineering, C 28 , 1304-1310 (2008).

18. Destainville, A., Champion, E. and Bernache-Assollante, D. Synthesis, characterization and thermal behaviour of apatite tricalcium phosphate, Materials Chemistry and Physics, 80, $269-277$ (2003).

19. Ratner, B., Hoffman, A. and Schoen, F. Biomaterials Scienc. An Introduction to Materials in Medicine. Second Edition, Academic Press, P. 851(2004).

20. Meejoo, S., Maneeprakorn, W. and Winotai, P., Phase and thermal stability of nanocrystalline hydroxyapatite prepared via microwave heating. Thermochimica Acta, 447, 115-120 (2006).

(Received 29/10/2014

accepted $16 / 3 / 2015$ 
PREPARATION, CHARACTERIZATION AND IN VITRO EVALUATION ... 55

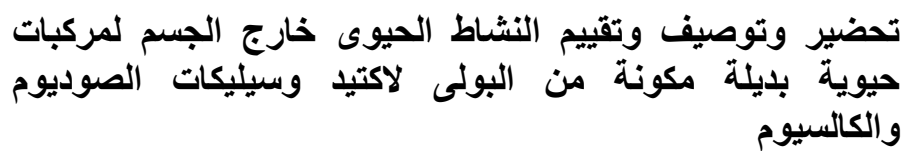
محمد اسماعيل الجوهرى، جيهان محمد كمال*،حر محمد عوض*، عبير محمود

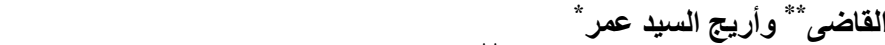

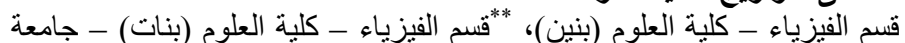

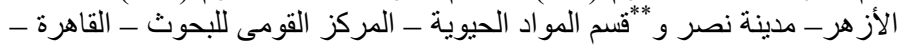

الهدف الرئيسى للاراسة الحالية هو تحضير مركبات مكونة من البولى لاكتيد وسيليكات الصوديوم والكالسيوم لاستخدامها في تطبيقات العئ العظام البديلة، بطريقة

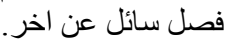

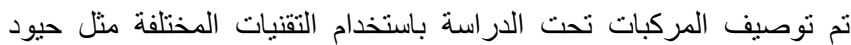

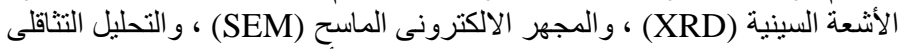
الحرارى (TGA) ، بالاضافة إلى دراسة طيف الأشعة تحت الحمر التهاء مع تحليل

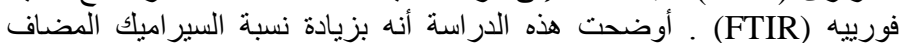

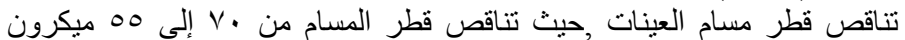

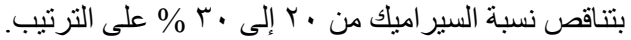

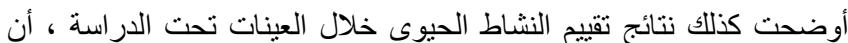

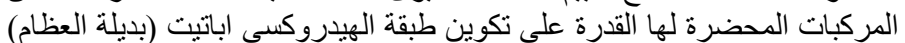
على سطحها ، مما يدل على امكانية تطبيقها في هندسة الأنسجة. 